\title{
Quantitative inheritance of resistance to Septoria tritici blotch in durum wheat in Tunisia
}

\author{
Samia Berraies ${ }^{1}$, Karim Ammar ${ }^{2}$, Mohamed Salah Gharbi ${ }^{3}$, Amor Yahyaoui $^{*}$, and Salah Rezgui ${ }^{4}$
}

\begin{abstract}
Septoria tritici blotch, causal agent Mycosphaerella graminicola (Fuckel) J. Schröt. (anamorph: Zymoseptoria tritici Desm.), is the major foliar disease of wheat (Triticum aestivum L.) in Tunisia causing frequent epidemics on T. turgidum L. var. durum (Desf.) Bowden, and important yield and grain quality losses. To determine the inheritance of resistance to septoria, a cross was made using resistant ('Salim') and susceptible ('Karim') cultivars. Parents, and the 149 derived recombinant lines, were tested for resistance to septoria under field conditions during the 2009 and 2010 crop seasons. The inheritance of resistance to septoria was quantitative where a continuous and normal distribution $(\mathrm{W}=0.93)$ was shown among segregate progenies. During 2009 and 2010 crop seasons, the mean disease severities of recombinant inbred lines (RILs) ranged from $29.1 \%$ to $41.8 \%$, respectively, and $53 \%$ of RILs were associated with lower disease severity than the mid-parent value. The severity was significantly affected by Genotype $\times$ Year interaction $(\mathrm{p}<0.01)$. Broad sense heritability was 0.55 suggesting a quantitative inheritance of resistance to M. graminicola. These results would imply that genetic resistance to STB could be attributed to additive gene effects. Thus, using identified sources of tolerance to STB in a breeding program would enhance the development of cultivars that are adapted to the prevailing isolates in field conditions.
\end{abstract}

Key words: Inheritance, quantitative resistance, recombinant inbred line population, Triticum durum, Zymoseptoria tritici.

\section{INTRODUCTION}

Septoria tritici blotch (STB) is currently the most important leaf blight disease of durum wheat (Triticum turgidum L. var. durum [Desf.] Bowden) in Tunisia, causing serious yield losses and affecting grain quality. In highly susceptible cultivars, STB can induce reduction in grain yield over 50\% during favorable conditions for the fungus (Eyal et al., 1987; Hardwick et al., 2001). In Tunisia, fungicide application is commonly used as a control strategy; however, this strategy is costly, not reliable from year to year, and has become less effective over the years. The lack of effectiveness of chemical treatment could be due to possible STB resistance to commonly used fungicides (Stergiopoulos et al., 2003; Fraaije et al., 2005; Mavroeidi and Shaw, 2005; Torriani

${ }^{1}$ Laboratoire de Génétique Moléculaire, Immunologie et Biotechnologie, Faculté des Sciences de Tunis, Campus Universitaire, 2092 El Manar, Tunis, Tunisia.

${ }^{2}$ International Maize and Wheat Improvement Center (CIMMYT) km 45 Carretera México-Veracruz El Batan, Texcoco, Estado de México, CP 56130. "Corresponding author (ah.yahyaoui@cgiar.org). ${ }^{3}$ Institut National de Recherche Agronomique de Tunis, Laboratoire de Grande Culture, Rue Hédi Karray, 2049, Tunis, Tunisia.

${ }^{4}$ Institut National Agronomique de Tunis, Laboratoire de Génétique et d'Amélioration des Plantes, 43 Avenue Charles Nicolle, 1002 Tunis, Tunisia.

Received: 14 September 2013.

Accepted: 10 December 2013.

doi:10.4067/S0718-58392014000100006 et al., 2009; Jorgensen et al., 2010). The prevalence of sexual recombination of the pathogen could also play a major role in the recurrent epidemics in durum wheat in Tunisia (Hamada et al., 2008; Boukef et al., 2012). The complexity of STB populations (Boukef et al., 2012) coupled with monoculture of highly susceptible cultivars, unpredictable rainfall, and excessive use of fungicides (two to three applications) imposes a well-planned integrated management of the STB disease where host resistance could play the lead role in this control measure.

Host resistance is a major component of sustainable integrated disease management (IDM) strategies; hence breeding for resistance to STB has been a major component of the national breeding program of Tunisia. However, the availability of effective sources of resistance is a key component of the breeding program, but limited sources of resistance are known and often confer only partial resistance (Goodwin, 2007; Arraiano et al., 2007).

Extensive screening for sources of resistance to STB has been undertaken within bread and durum wheat lines and with their wild relatives (Rosielle, 1972; Krupinsky et al., 1977; Eyal et al., 1983; Yechilevich-Auster et al., 1983; May and Lagudah, 1992; McKendry and Henke, 1994). Several investigations reported that STB resistance is either quantitative or qualitative, and the inheritance of the resistance may follow dominant, partially dominant, epistatistic, recessive, additive, and non-additive gene action (McCartney et al., 2002; Chartrain et al., 2009). Qualitative resistance is isolate-specific, may 
be monogenic or oligogenic, and the near-complete nature of resistance follows the gene-for-gene model (Somasco et al., 1996; Arraiano, 2001; McCartney et al., 2002; Brading et al., 2002). Other authors claimed that resistance was often quantitative, polygenic and provides partial resistance to a wide variety of isolates (Jlibene et al., 1994; Simon and Cordo, 1998; Zhang et al., 2001; Chartrain et al., 2004; Arraiano and Brown, 2006). The partial resistance is durable under field conditions and is expressed as a reduction in epidemic development (Chartrain et al., 2004).

During the last decade 18 major resistance genes (Stb1Stb18) to STB have been identified and mapped in the wheat genome (Arraiano et al., 2007; Goodwin, 2007; Chartrain et al., 2009; Tabib Ghaffary et al., 2011a; 2011b). These developments have greatly improved the efficiency of marker-assisted selection in bread wheat. However, only few studies on the inheritance of STB in durum wheat have been reported (Gilchrist et al., 1993). The findings from these studies indicate that resistance to STB can be explained by models involving additive and dominant gene effects. Several authors found that the additive gene action is more important than that of dominance (Van Ginkel and Scharen, 1987; 1988; Gilchrist et al., 1993); whereas epistasis was of minimal importance. In recent years, some durum wheat varieties, with improved resistance to STB, have been released in Tunisia. These cultivars can be also be used as parental material to eventually diversify resistance sources in breeding for resistance to STB. The objective of this study was to investigate the nature of gene action governing the expression of the resistance to STB using recombinant inbred line (RIL) population derived from the cross between a resistant cv. Salim and the highly susceptible cv. Karim.

\section{MATERIALS AND METHODS}

\section{Plant material and population development}

Recombinant inbred lines (RILs) were developed from the cross involving 'Salim' as the resistant parent and the susceptible 'Karim'. The resistant 'Salim' was released in Tunisia in 2009 and showed good level of resistance to STB over at least the last $5 \mathrm{yr}$ and at different locations within the country (unpublished data). The susceptible cultivar covers more than $60 \%$ of the durum wheat area and was appreciated because of its stable yields and good industrial quality. Hence improving 'Karim' resistance is highly sought by breeders to respond to farmers' needs.

After an initial cross between the two parents 'Salim' $x$ 'Karim', $F_{1}$ and $F_{2}$ seeds were produced. A single seed was selected from each resistant $\mathrm{F}_{2}$ plant and used to produce the $\mathrm{F}_{3}$ generation. The development of the RILs population was generated using this single seed descent (SSD) approach in subsequent $\mathrm{F}_{4}$ and $\mathrm{F}_{5}$ generations. The population used in our study consisted of 149 RILs $\left(\mathrm{F}_{6}\right)$. Adult plants in $\mathrm{F}_{6}$ generation were assessed for reaction to STB.

\section{Experimental trials}

The evaluation of 149 RILs (recombinant inbred lines) was conducted under field conditions at the Institut National de Recherches Agronomiques (INRA) Beja experimental station, located at North West Tunisia (36 43'30" N, $\left.9^{\circ} 10^{\prime} 55^{\prime \prime} \mathrm{E} ; 9^{\circ} 11^{\prime} 20^{\prime \prime}\right)$. This station is located in the sub-humid region characterized by high rainfall with mild winter which are favorable conditions for natural infection of septoria. For the RILs populations and the parental lines, experiments were seeded in an augmented design (Petersen, 1994) with seven blocks. Parents were used as controls and were replicated as single 1-m row in each block and the remaining rows of the block were assigned to single 1-m row of RILs. Experiments were repeated in 2008-2009 and 2009-2010 growing seasons using augmented design as experimental design.

The experiments were inoculated by spraying plants at late tillering stage (GS22) (Zadoks et al., 1974) with a suspension of a mixture of Septoria isolates originating from the same field. The inoculum was produced by growing the fungus in liquid yeast glucose medium for 5 to $8 \mathrm{~d}$. The spore suspension was adjusted to a concentration of $10^{6}$ spore $\mathrm{mL}^{-1}$ and $0.5 \mathrm{~mL} \mathrm{~L}^{-1}$ Tween 20 was added before spraying with an air pumped sprayer.

\section{Disease evaluations}

The reaction of 149 RILs and parental lines to the artificial inoculation was recorded at early grain filling stage (GS71) (Zadoks et al., 1974) using modified Saari and Prescott's double-digit (00 99) scoring method that was based on the severity scale to assess wheat foliar diseases (Saari and Prescott, 1975; Eyal et al., 1987). The first digit (D1) indicates the relative height of the disease on the plant and corresponds to the vertical disease progression using the original 0-9 Saari-Prescott scale (Saari and Prescott, 1975) as a measure. The second digit (D2) refers to severity measured as diseased leaf area. For each score, the disease severity percentage was calculated based on the following formula (Sharma and Duveiller, 2007):

$\%$ Disease severity $(\mathrm{DS})=(\mathrm{D} 1 / 9) \times(\mathrm{D} 2 / 9) \times 100$.

The RILs were classified into three categories: susceptible lines with severity responses similar to the susceptible parent 'Karim', relatively resistant lines with severity responses similar to the resistant parent 'Salim', and lines segregating with intermediate response to STB.

\section{Statistical analysis}

The ANOVA for disease severity was performed using PROC GLM with the option pdiff using the unilateral $\mathrm{t}$ test $\left(\mathrm{LSI}_{0.05}, \mathrm{SAS}, 8.0\right)$ to identify resistant lines. The frequency distribution of the RILs was tested for normality by the $W$-test (Shapiro and Wilks, 1965) PROC UNIVARIATE of SAS $(p<0.05)$. The frequency distributions and normality curves for RILs STB reactions were generated using STATISTICA 6.0. Broad sense heritability (BSH) was estimated with the equation 
BSH $=\delta_{\mathrm{g}}{ }^{2} /\left(\delta_{\mathrm{g}}{ }^{2}+\delta_{\mathrm{gy}} / \mathrm{ry}+\delta_{\mathrm{e}}{ }^{2} / \mathrm{r}\right)$, where $\delta_{\mathrm{g}}{ }^{2}$ was the genotypic variance within the RILs; $\delta_{\mathrm{e}}{ }^{2}$ was the error variance; and $r$ and $\mathrm{y}$ was the number of replicates and years respectively. The $\delta_{\mathrm{g}}{ }^{2}$ and $\delta_{\mathrm{e}}{ }^{2}$ were estimated using PROC VARCOMP of SAS 8.0.

\section{RESULTS}

The frequency distribution of better resistant RILs to STB as compared to 'Salim' was higher during the 2009 cropping season compared to 2010 (Table 1). Although the frequency of RILs with a susceptible response to STB was almost twice that those noted during 2010, a higher number of RILs with intermediate response between the parental lines was observed in 2010 experiment. These favorable conditions for disease development induced higher disease severity scores for both parental cultivars in 2010. The STB severities for 'Karim' ranged from 39.5\% to $69.5 \%$ during 2009 and 2010 respectively. However, for 'Salim' the response to STB infection ranged from $6.3 \%$ to $8.9 \%$ during both seasons, respectively. These differences in disease responses could be attributed to the seasonal conditions, particularly rainfall and temperature regimes that prevailed during winter 2010. It is apparent, that, the higher scores of disease severity in 2010 enabled greater discrimination between RILs as compared to parental mean values that were lower during the 2009 than 2010 crop season (Table 1).

The distribution of RILs population and parental lines was also studied to discriminate between resistant and susceptible groups and identify potential transgressive segregants resistant to STB. The distribution analysis indicated that the mean of disease severity of the parental lines 'Karim' and 'Salim' during both crop seasons showed significant differences in susceptibility (54.5\%) and resistance $(7.6 \%)$ respectively. The mean DS of RILs during 2009 and 2010 were $29.1 \%$ and $41.8 \%$, respectively; these means are comparable to the midparent value (MPV) suggesting that resistance is probably under polygenic control with additive loci (Table 2). The distribution of RILs (recombinant inbred lines) was continuous for STB severity suggesting polygenic control of resistance and quantitative inheritance (Figures 1a, 1b, and 1c). The Shapiro-Wilks W-test $(\mathrm{W}=0.93)$ was clearly significant $(\mathrm{p}<0.0001)$ and revealed that RILs data fit a
Table 2. Tests for normality, means of disease severity (DS) in 149 recombinant inbred lines (RILs) derived from the wheat cross 'Salim' x 'Karim' assessed during two cropping seasons: 2009 and 2010.

\begin{tabular}{|c|c|c|c|c|c|c|c|}
\hline \multirow[b]{2}{*}{ Parameter } & \multicolumn{3}{|c|}{ Normality test } & \multicolumn{2}{|c|}{$\begin{array}{c}\text { Mean of } \\
\text { parents }\end{array}$} & \multicolumn{2}{|c|}{ Mean } \\
\hline & W & $\mathrm{P}$ & Skewness & Karim & Salim & MPV & RILs \\
\hline DS 2009 & 0.87 & $<0.0001$ & 1.11 & 39.51 & 6.35 & 22.93 & 29.12 \\
\hline DS 2010 & 0.95 & 0.0002 & 0.40 & 69.49 & 8.99 & 39.24 & 41.86 \\
\hline DS $2009 / 2010$ & 0.93 & $<0.0001$ & 0.98 & 54.50 & 7.67 & 31.08 & 35.49 \\
\hline
\end{tabular}

W corresponds to the Shapiro-Wilks test; MPV corresponds to mid parent value.

normal distribution (Table 2). Skewness value indicates that positive deviation from zero would suggest that distribution is skewed towards resistance. In our study, the reactions of RILs to STB infection showed that most of them appeared to have intermediate response to infection by $S$. tritici and were slightly skewed toward the mean of the resistant parent. On the basis of frequency distribution and normality test, results indicated that resistance to STB is most likely controlled by several genes.

The ANOVA (Table 3) showed that year of evaluation, RILs and the interaction RILs $\times$ year were highly significant $(\mathrm{p}<0.01)$. These results also support the conclusion that the 2010 crop season enhanced disease severity as compared to 2009 . The mean disease ranged from $5.4 \%$ to $90.9 \%$ showing a wide range of phenotypic variation in the population.

During both seasons, 67 RILs were associated with lower disease severity as compared to the MPV. However, we observed that only three lines were consistently more resistant than the resistant parent 'Salim' during these $2 \mathrm{yr}$ even though the relative severity reduction noted within these lines did not differ significantly from the resistant parent $\left(\mathrm{LSI}_{0.05}=12.34\right)$. The average disease score ranged from $2.4 \%$ to $8.3 \%$ for the lines 8,23 , and 41 . The observed transgressive segregation toward resistance in the RILs suggested that resistance to STB was conferred by several genes that have an additive effect. This result has been attributed to the skewed distribution of rating for STB toward the resistant 'Salim'. However the susceptible parental line tended to transmit important frequency of septoria susceptible genes to the derived RILs.

Broad sense heritability was 0.55 suggesting a quantitative inheritance of septoria resistance. This result is expected since severity indices and overall assessment were carried out under field conditions. This result would

Table 1. Disease severity (DS) distribution and mid-range values assessed during 2009 and 2010 cropping seasons in recombinant inbred lines (RILs) and parental lines of wheat 'Salim' (resistant cultivar) and 'Karim' (susceptible cultivar).

\begin{tabular}{|c|c|c|c|c|}
\hline \multicolumn{2}{|c|}{ Cropping seasons } & \multirow{2}{*}{$\begin{array}{c}\mathrm{DS}_{\mathrm{RILs}} \leq \mathrm{DS}_{\text {Salim }} \\
31\end{array}$} & \multirow{2}{*}{$\frac{\mathrm{DS}_{\text {Salim }}<\mathrm{DS}_{\text {RILs }}<\mathrm{DS}_{\text {Karim }}}{77}$} & \multirow{2}{*}{$\begin{array}{c}\mathrm{DS}_{\mathrm{RILs}} \geq \mathrm{DS}_{\text {Karim }} \\
41\end{array}$} \\
\hline Beja 2009 & Number of lines & & & \\
\hline & Mean DS & 3.05 & 21.31 & 63.45 \\
\hline & Standard deviation & 1.39 & 9.34 & 19.75 \\
\hline \multirow[t]{3}{*}{ Beja 2010} & Number of lines & 5 & 118 & 26 \\
\hline & Mean DS & 7.39 & 35.86 & 75.73 \\
\hline & Standard deviation & 2.25 & 14.60 & 7.01 \\
\hline \multirow[t]{3}{*}{ Beja 2009/2010 } & Number of lines & 3 & 129 & 17 \\
\hline & Mean DS & 6.28 & 33.11 & 73.85 \\
\hline & Standard deviation & 0.96 & 11.92 & 12.12 \\
\hline
\end{tabular}



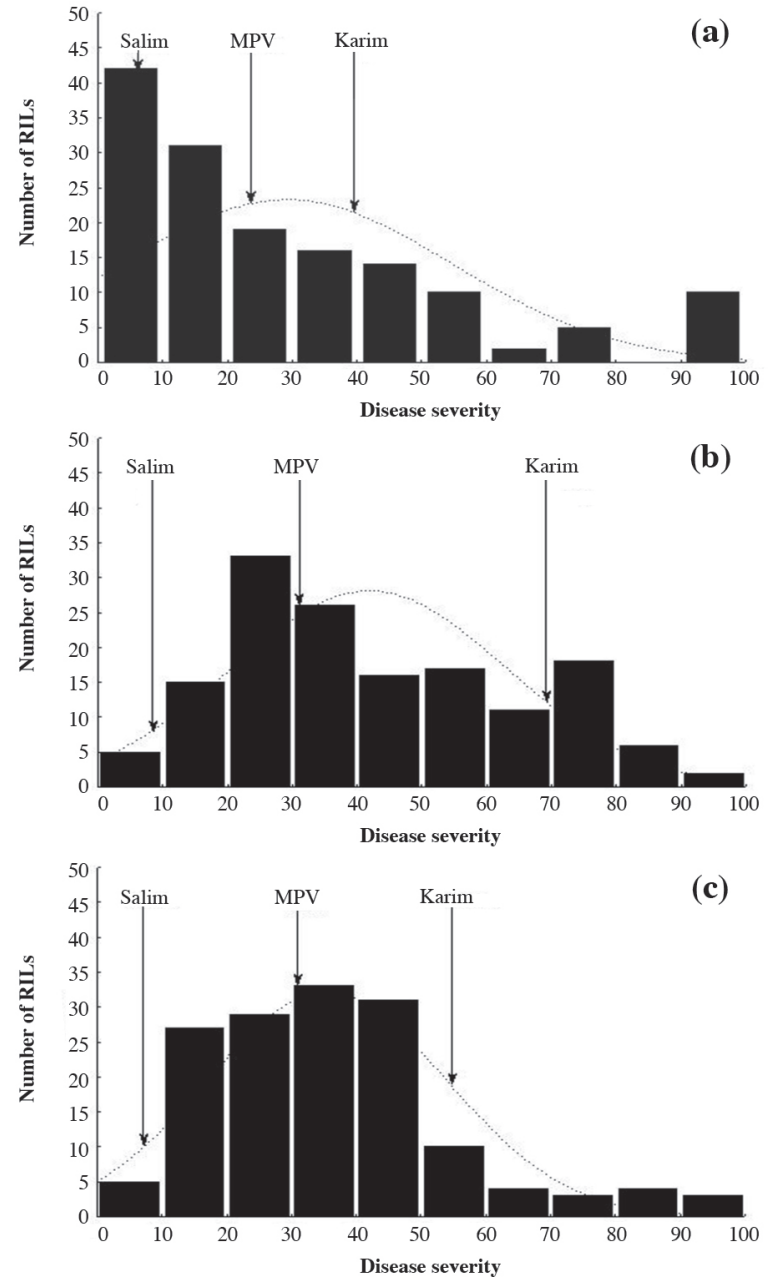

Histograms: frequency distribution; dashed line curve: normal probability distribution; arrows indicate the mean value of both parental lines 'Karim' and 'Salim' and mid-parent value (MPV).

Figure 1. Frequency distribution of the mean disease severity for Septoria tritici blotch (STB) reaction among 149 recombinant inbred lines (RILs) from the cross 'Salim' $x$ 'Karim' evaluated during 2009 (a), 2010 (b), and (c) both cropping seasons.

Table 3. Disease severity (DS) mean square of 149 recombinant inbred lines (RILs) derived from the cross between resistant ('Salim') and susceptible ('Karim') wheat cultivars evaluated during 2009 and 2010 cropping seasons.

\begin{tabular}{lrc}
\hline Source & df & Mean square \\
\hline Year & 1 & $13464.95^{* *}$ \\
Block (Year) & 12 & $67.59^{\text {ns }}$ \\
RIL & 148 & $487.38^{* *}$ \\
Year $\times$ RIL & 148 & $260.78^{* * *}$ \\
Error & 12 & 47.92 \\
\hline
\end{tabular}

CV 20.15 .

";** Significant differences at $\mathrm{p}<0.05$ and $\mathrm{p}<0.01$ respectively; ns: non significant at 0.05 level.

be attributed to the various components of septoria population prevailing in the field and the response could be perceived as an average severity score that would encompass the mean response of all isolates characterized by differential virulence patterns. Moreover, derived
RILs may have displayed several resistant genes in one single line that have an additive effect as depicted by transgressive segregants (Table 1).

\section{DISCUSSION}

Genetic studies on inheritance of resistance to STB have generally been conducted at the seedling growth stage in the greenhouse and have been oriented towards examining the effects of simple Mendelian inheritance using single gene model (Arama et al., 2000). In practical plant breeding situations, screening for resistance to STB is carried out under field condition allowing full exposure of the genetic material to real natural multi-virulence pathogen population. Recombinant inbred lines (RILs) used in this investigation were evaluated under inductive septoria infection conditions that were prevailing at Beja experimental station. Furthermore, inoculation has been carried out at tillering growth stage to enhance infection. The increase of susceptibility in 2010 could be result from a shift in virulence of the STB population within the same field as outlined by Berraies et al. (2013). This could be also explained by weather conditions during each cropping season which determine the differences of resistant and susceptible RILs numbers during 2009 and 2010 crop seasons (Table 1$)$. However, only three lines $(8,23$, and 41$)$ were consistently more resistant than the resistant parent during both cropping seasons. These results suggest that effective selection could be achieved only under higher disease pressure as occurred in 2010.

The mean values of RILs were almost equal to the average of the mid-parent value (Table 2), confirming that resistance to STB is under polygenic control combined with an additive effect (Kahraman et al., 2004). Moreover, the frequency distribution for the 149 RILs was not consistent with a single gene model for STB resistance and was continuous and followed normal distributions. Our results support the polygenic and quantitative inheritance of resistance to STB (Van Ginkel and Scharen, 1987; 1988; Lynch and Walsh, 1998; Tabib Ghaffary et al., 2011b). The relative skeweness toward the resistant parent during both seasons (Figures 1a, 1b, and 1c) would imply that multiple genes with complementary additive effects but with partial dominance toward resistance are conferring resistance derived from 'Salim'.

Many breeding programs and strategies have been developed to improve cultivar resistance aiming to sustain resistance (Delourme et al., 2006; Rimmer, 2006; Stuthman et al., 2007) that would remain effective over many years in an environment conducive to STB epidemics.

The relative frequency of the emergence of new virulent strains attributed to the frequent genetic recombination (Boukef et al., 2011) represent a major risk for resistance breakdown (McDonald and Linde, 2002), resulting in a succession of epidemic cycles particularly when rainfall 
and mild temperature are favorable for development of STB. Therefore the increase in virulent genes within the pathogen population may favor increased level of aggressiveness and would contribute to shorten the length of resistance periods of the host. The quantitative inheritance of resistance found in our study could allow lower selection pressure on pathogen populations that may eventually adapt, but over longer time, to multiple resistances encountered in RILs. Quantitative resistance is usually controlled by several genes. For one location, it is apparent that more factors are involved in the resistance because of disease severity, the low variability among the RILs, and consequently the low additive variance. Under the assumption of absence of epistasis and linkage, resistance gene action in RILs is additive since the population size could be considered as large and contain the extreme resistant genotypes (Choo and Reinbergs, 1982; Snape et al., 1984).

In this study, the sample size of 149 RILs may give a high probability that the best recombinants are included in the population when the resistance is controlled by several genes. However, another assumption of RILs model assumes that all the alleles for resistance come from the resistant parent. The observation of transgression may indicate that the susceptible parent 'Karim' may also have alleles for resistance of minor effects associated. The relatively lower transgressive segregants along with lower heritability estimates support the quantitative inheritance of resistance to STB observed in these RILs. Moreover, these estimates indicate that differential resistance gene expression is likely to occur under both genetic and growing condition as expressed by high genotype by year interaction $(\mathrm{G} \times \mathrm{Y})$ (Table 3). The continuous variations in the response of RILs to STB suggest that resistance is conferred by additive effects of these genes. Hence, considering the relatively greater evolutionary aspects of Zymoseptoria tritici (M. graminicola) and the high genetic diversity attributed to several factors (Linde et al., 2002; Zhan et al., 2003); quantitative breeding scheme could be an alternative to develop cultivars with more durable resistance. The use of molecular markers based tools would improve selection efficiency for sustainable resistance to STB and enhance the introgression of individual resistant genes into susceptible but high yielding cultivars (Chartrain et al., 2009). However, marker assisted selection should be combined with consistent scoring methods to develop tolerant/resistant cultivars to STB (Chartrain et al., 2004). The resistance to STB should be assessed under field conditions to show the relative efficiency and durability of identified resistant cultivar.

\section{CONCLUSIONS}

Breeding for resistance to Septoria tritici blotch (STB) under field conditions would reduce infection level and enhance the development of tolerant cultivars. Our results suggest that resistance to septoria leaf blotch (STB) in this population is under polygenic control and quantitatively inherited. In order to design efficient breeding strategies to enhance resistance to STB in durum wheat, the genetic variance and heritability estimates indicated that the environment represents a major component inducing various virulent genes within the pathogen within the same field. Rainy winter coupled with mild temperature along with prevalence of virulent populations of STB particularly during 2010 cropping season, appeared to explain most of the environmental component. However, phenotypic selection is still possible using the most susceptible cultivar as reference and identifying recombinant inbred lines segregating progenies. Further research is needed to identify the chromosomal location of this resistance to STB. However, pyramiding of various resistant genes in adapted germplasm could be efficient to select for resistance under field conditions where a mixture of virulence of STB is prevailing.

\section{LITERATURE CITED}

Arama,P.F., J.E. Parlevliet, and C.H. VanSilhout. 2000. Transgressive segregation for resistance in wheat to Septoria tritici blotch. African Crop Science Journal 8:213-222.

Arraiano, L.S. 2001. Genetics of resistance of wheat to Septoria tritici blotch. Dissertation. University of East Anglia, Norfolk, UK.

Arraiano, L.S., and J.K.M. Brown. 2006. Identification of isolatespecific and partial resistance to septoria tritici blotch in 238 European wheat cultivars and breeding lines. Plant Pathology 55:726-738.

Arraiano, L.S., L. Chartrain, E. Bossolini, H.N. Slatter, B. Keller, and J.K.M. Brown. 2007. A gene in European wheat cultivars for resistance to an African isolate of Mycosphaerella graminicola. Plant Pathology 56:73-78.

Berraies, S., M.S. Gharbi, F. Belzile, A. Yahyaoui, M.R. Hajlaoui, M. Trifi, et al. 2013. High genetic diversity of Mycospaherella graminicola (Zymoseptoria tritici) from a single wheat field in Tunisia as revealed by SSR markers. African Journal of Biotechnology 12:1344-1349.

Boukef, S., B.A. McDonald, A. Yahyaoui, S. Rezgui, and P.C. Brunner. 2012. Frequency of mutations associated with fungicide resistance and population structure of Mycosphaerella graminicola in Tunisia. European Journal of Plant Pathology 132:111-122.

Boukef, S., A. Yahyaoui, B.A. McDonald, P.C. Brunner, and S. Rezgui. 2011. Evaluation of fungicide resistance of Mycosphaerella graminicola isolates surveyed from Tunisian wheat fields. Revue de l'INAT 26:19-35.

Brading, P.A., E.C.P. Verstappen, G.H.J. Kema, and J.K.M. Brown. 2002. A gene-for-gene relationship between wheat and Mycosphaerella graminicola, the Septoria tritici blotch pathogen. Phytopathology 92:439-445.

Chartrain, L., P.A. Brading, J.P. Widdowson, and J.K.M. Brown. 2004. Partial resistance to Septoria tritici blotch (Mycosphaerella graminicola) in wheat cultivars Arina and Riband. Phytopathology 94:497-504

Chartrain, L., P. Sourdille, M. Bernard, and J.K.M. Brown. 2009. Identification and location of Stb9, a gene for resistance to septoria tritici blotch in wheat cultivars Courtot and Tonic. Plant Pathology 58:547-555.

Choo, T.M., and E. Reinbergs. 1982. Estimation of the number of genes in doubled haploid populations of barley (Hordeum vulgare). Canadian Journal of Genetics and Cytology 24:337-341. 
Delourme, R., A.M. Chevre, H. Brun, T. Rouxel, M.H. Balesdent, J.S. Dias, et al. 2006. Major gene and polygenic resistance to Leptosphaeria maculans in oil seed rape (Brassica napus). European Journal of Plant Pathology 114:41-52.

Eyal, Z., A.L. Scharen, J.M. Prescott, and M. Van Ginkel. 1987. The Septoria diseases of wheat: Concepts and methods of disease management. CIMMYT, Mexico D.F., Mexico.

Eyal, Z., I. Wahl, and J.M. Prescott. 1983. Evaluation of germplasm response to septoria leaf blotch of wheat. Euphytica 32:439-446.

Fraaije, B.A., H.J. Cools, and J. Fountaine. 2005. Role of ascospores in further spread of QoI-resistant cytochrome b alleles (G143A) in field populations of Mycosphaerella graminicola. Phytopathology 95:933-941.

Gilchrist, L.I., O.S. Abdalla, and C. Velazquez. 1993. Inheritance of resistance to Seporia tritici leaf blotch in selected durum wheat lines. Proceeding of the Septoria tritici Workshop, Mexico D.F. 20-24 September. CIMMYT, Mexico D.F., Mexico.

Goodwin, S.B. 2007. Back to basics and beyond: increasing the level of resistance to Septoria tritici blotch in wheat. Australasian Plant Pathology 36:532-538.

Hamada, W., W. Zouid, L. Somai, and M. Harrabi. 2008. Evaluation of Septoria tritici-wheat interaction in Tunisia. Proceeding of the 7th International Mycosphaerella and Stagonospora Symposium, Ascona, Switzerland. August 18-22. ETH Zurich, Plant Pathology Group, Zurich, Germany.

Hardwick, N., D. Jones, and J. Slough. 2001. Factors affecting diseases of winter wheat in England and Wales, 1989-1998. Plant Pathology 50:453-462.

Jlibene, M., J.P. Gustafson, and S. Rajaram. 1994. Inheritance of resistance to Mycosphaerella graminicola in hexaploid wheat. Plant Breeding 112:301-310.

Jorgensen, L.N., M.S. Hovmoller, and J.G. Hansen. 2010. EuroWheat.org A support to integrated disease management in wheat. Outlooks on Pest Management 21:173-176.

Kahraman, A., I. Kusmenoglu, N. Aydin, A. Aydogan, W. Erskine, and F.J. Muehlbauer. 2004. Genetics of winter hardiness in 10 lentil recombinant inbred line populations. Crop Science Society of America, Madison, Wisconsin, USA.

Krupinsky, J.M., J.C. Craddock, and A.L. Scharen. 1977. Septoria resistance in wheat. Plant Disease Report 61:632-636.

Linde, C.C., J.Zhan, and B.A. McDonald. 2002. Population structure of Mycosphaerella graminicola: from lesions to continents. Phytopathology 92:946-955.

Lynch, M., and B. Walsh. 1998. Genetics and analysis of quantitative traits. Sinauer Associates, Sunderland, Massachusetts, USA.

Mavroeidi, I., and M.W. Shaw. 2005. Sensitivity distributions and cross-resistance patterns of Mycosphaerella graminicola to fluquinconazole, prochloraz and azoxystrobin over a period of 9 years. Crop Protection 24:259-266.

May, C.E., and E.S. Lagudah. 1992. Inheritance in hexaploid wheat of septoria tritici blotch resistance and other characteristics derived from Triticum tauschii. Australian Journal of Agriculture Research 43:433-442.

McCartney, C.A.,A.L. Brûlé-Babel, and L. Lamari. 2002. Inheritance of race specific resistance to Mycosphaerella graminicola in wheat. Phytopathology 92:138-144.

McDonald, B.A., and C. Linde. 2002. Pathogen population genetics, evolutionary potential and durable resistance. Annual Review of Phytopathology 40:349-379.

McKendry, A.L., and G.E. Henke. 1994. Evaluation of wheat relatives for resistance to septoria tritici blotch. Crop Science 34:1080-1084.
Petersen, R.G. 1994. Agricultural field experiments design and analysis. Marcel Dekker, New York, USA.

Rimmer, S.R. 2006. Resistance genes to Leptosphaeria maculans in Brassica napus. Canadian Journal Plant Pathology 28:S288-S297.

Rosielle, A.A. 1972. Sources of resistance in wheat to speckled leaf blotch caused by Septoria tritici. Euphytica 21:152-161.

Saari, E.E., and J.M. Prescott. 1975. A scale for appraising the foliar intensity of wheat disease. Plant Disease Reporter 59:377-380.

Shapiro, S.S., and M.B. Wilks. 1965. An analysis of variance test for normality (complete samples). Biometrika 52:591-611.

Sharma, R.C., and E. Duveiller. 2007. Advancement toward new Spot Blotch resistant wheats in south Asia. Crop Science 47:961968.

Simon, M.R., and C.A. Cordo. 1998. Diallel analysis of four resistance components to Septoria tritici in six crosses of wheat (Triticum aestivum). Plant Breeding 117:123-126.

Somasco, O.A., C.O. Qualset, and D.G. Gilchrist. 1996. Single-gene resistance to Septoria tritici blotch in the spring wheat cultivar 'Tadinia'. Plant Breeding 115:261-267.

Snape, J.W., A.J. Wright, and E. Simpson. 1984. Methods for estimating gene numbers for quantitative characters using doubled haploid lines. Theoretical and Applied Genetics 67:143-148.

Stergiopoulos, I., J.G.M. Van Nistelrooy, G.H.J. Kema, and M.A De Waard. 2003. Multiple mechanisms account for variation in base-line sensitivity to azole fungicides in field isolates of Mycosphaerella graminicola. Pest Management Science 59:13331343.

Stuthman, D.D., J.J. Leonard, and J. Miller-Garvin. 2007. Breeding crops for durable resistance to disease. Advances in Agronomy 95:319-367

Tabib Ghaffary, S.M., J.D. Faris, T.L. Friesen, R.G.F. Visser, T.A. Van der Lee, O. Robert, et al. 2011a. New broad-spectrum resistance to septoria tritici blotch derived from synthetic hexaploid wheat Theoretical and Applied Genetics. doi:10.1007/s00122-011-16927.

Tabib Ghaffary, S.M., O. Robert, V. Laurent, P. Lonnet, E. Margalé, T.A. Van der Lee, et al. 2011b. Genetic analysis of resistance to septoria tritici blotch in the French winter wheat cultivars Balance and Apache. Theoretical and Applied Genetics 123:741-754 doi:10.1007/s00122-011-1623-7.

Torriani, S., P. Brunner, B.A. McDonald, and H. Sierotzki. 2009. QoI resistance emerged independently at least 4 times in European populations of Mycosphaerella graminicola. Pest Management Science 65:155-162.

Van Ginkel, M., and A.L. Scharen. 1987. Generation mean analysis and heritabilities of resistance to Septoria tritici in durum wheat. Phytopathology 77:1629-1633.

Van Ginkel, M., and A.L. Scharen. 1988. Diallel analysis of resistance to Septoria tritici isolates in durum wheat. Euphytica 38:31-37.

Yechilevich-Auster, M., E. Levi, and Z. Eyal. 1983. Assessment of interactions between cultivated and wild wheats and Septoria tritici. Phytopathology 73:1077-1083.

Zadoks, J.C., T.T. Chang, and C.F. Konzak. 1974. A decimal code for the growth stages of cereals. Weed Research 14:415-421.

Zhan, J., R.E. Pettway, and B.A. McDonald. 2003. The global genetic structure of the wheat pathogen Mycosphaerella graminicola is characterized by high nuclear diversity, low mitochondrial diversity, regular recombination, and gene flow. Fungal Genetic and Biology 38:286-297.

Zhang, X., S.D. Haley, and Y. Jin. 2001. Inheritance of septoria tritici blotch resistance in winter wheat. Crop Science 41:323-326. 